\title{
Most Severe Chronic Stressor
}

National Cancer Institute

\section{Source}

National Cancer Institute. Most Severe Chronic Stressor. NCI Thesaurus. Code C124441.

The agent, stimulus, activity, or event that causes stress with a chronic frequency, which has the highest level of severity. 